This item was submitted to Loughborough's Research Repository by the author.

Items in Figshare are protected by copyright, with all rights reserved, unless otherwise indicated.

\title{
Theory-based model of factors affecting information overload
}

PLEASE CITE THE PUBLISHED VERSION

http://dx.doi.org/10.1016/j.jijfomgt.2012.04.006

PUBLISHER

(c) Elsevier

VERSION

AM (Accepted Manuscript)

LICENCE

CC BY-NC-ND 4.0

REPOSITORY RECORD

Jackson, Thomas, and Pourya Farzaneh. 2019. "Theory-based Model of Factors Affecting Information Overload". figshare. https://hdl.handle.net/2134/11702. 
This item was submitted to Loughborough's Institutional Repository (https://dspace.lboro.ac.uk/) by the author and is made available under the following Creative Commons Licence conditions.

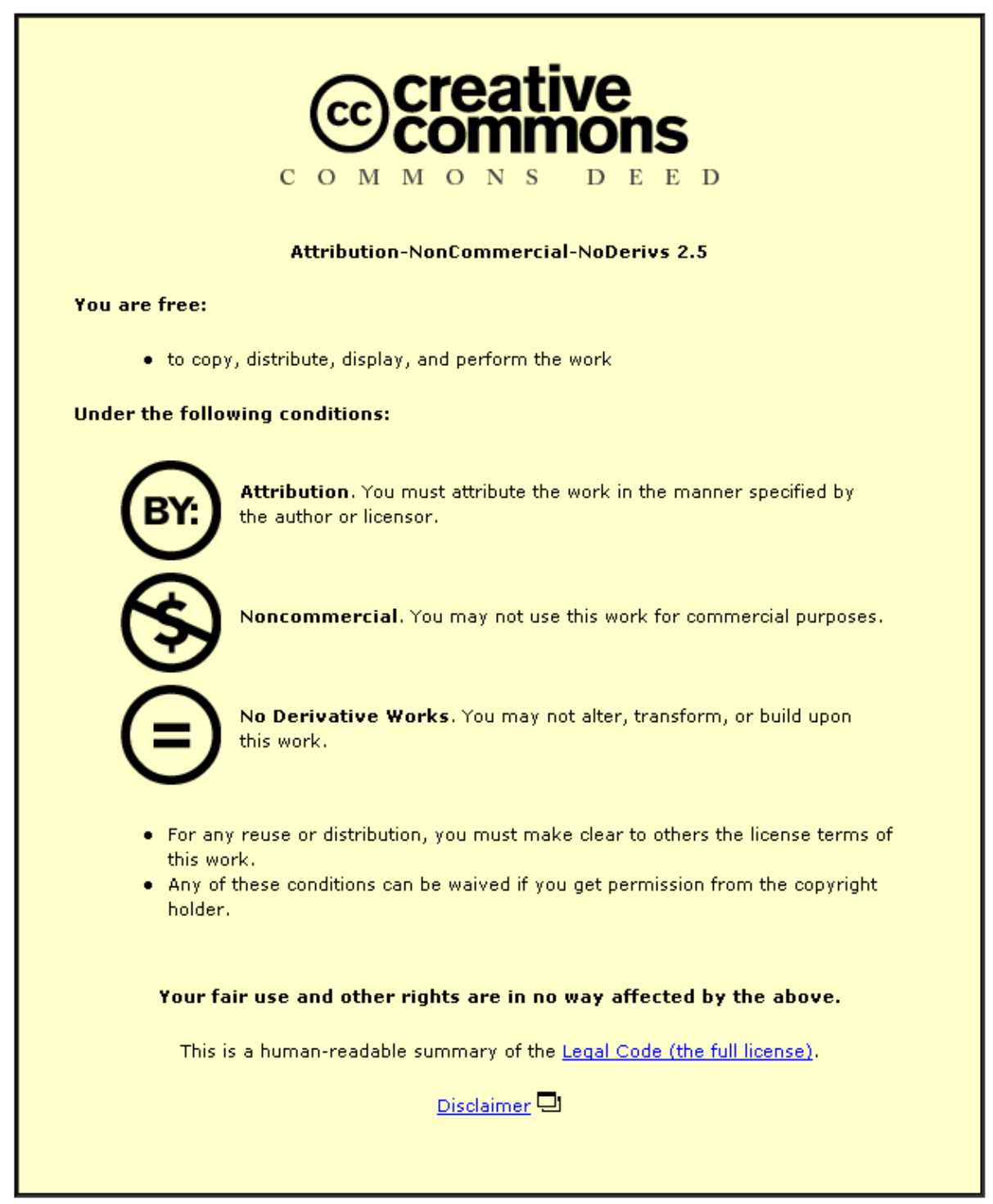

For the full text of this licence, please go to: http://creativecommons.org/licenses/by-nc-nd/2.5/ 


\title{
Theory-based Model of Factors affecting Information Overload
}

\author{
Dr Thomas W. Jackson* and Pourya Farzaneh
}

\author{
Information Science Department, Loughborough University, Loughborough, \\ Leicestershire LE11 3TU, UK. *t.w.jackson@lboro.ac.uk (+44) 1509635666
}

As the volume of available information increases, individuals and organisations become overwhelmed by the plethora of information. This can reduce productivity and performance, hinder learning and innovation, affect decision making and well-being and cost organisations large amounts of money. This paper develops a new theory-based model of factors affecting information overload and provides a formula for calculating the extent of overload, potentially of use as a diagnostic tool supporting individual or organisational development.

Two methods for categorising factors that contribute to the overload phenomena are introduced. The first method separates those factors based on their direct or indirect effect on information overload, called intrinsic and extraneous factors respectively. The second method divides factors based on whether or not the factor increases or decreases information overload likelihood and tags those factors in terms of 'For' or 'Against'. These new methods for categorisation not only assisted in the development of the conceptual model and in creating the formula, but could be used in other aspects of information overload research, such as finding and evaluating countermeasures to information overload. The model and the formula presented in the paper provide a significant contribution to the information overload body of research.

Keywords: Information Overload Model; Information Overload Formula; Conceptual models; Theorybuilding

\section{Introduction}

In recent times the world has witnessed a dramatic increase in the amount of formal and informal information produced in a crowded "information society", in which the amount of information being created every two days is equivalent to that created from the dawn of civilization until year 2003 (Seigler, 2003). This means that one of the fastest growing quantities on this planet is the amount of information being produced and information overload is recognised as potentially a big problem for society. Twitter, for example, reported that an average of 200 million tweets were posted during June 2011 - akin to a 10 million-page book that would take 31 years to read - compared with 65 million in June 2010 and only 2 million in January 2009. There is a varied body of research into information overload across many different subjects but no one agreed definition of the term (Edmunds \& Morris, 2000); various definitions have instead been put forward, all with similar themes. Feather (1998) suggested that information overload could be described as the point where there is so much information it could no longer be used effectively, while Bawden et al. (1999) suggested that information overload occurred when potentially useful information received became a hindrance rather than a help.

The term information overload is a common phrase used in today's society and one that is seemingly seen as a recent addition to the vocabulary. The concept of information overload has, however, been around for some time. Ackoff (1997) researched the abundance of irrelevant information, describing one of the deficiencies of Management Information Systems as being designed 'on the assumption that the critical deficiency under which most managers operate is the lack of relevant information'. Edmunds and Morris (2000) claimed that the phenomenon could date back as far as the early 1800 s, citing Hayes on the rapid growth of case law. The example provided was that in 1810 there were 18 volumes of reports and by 1845 there were 800 . By 1885 there were nearly 
3800, demonstrating the expanding nature of information. Klapp (1986) stated that one of the first social scientists to notice this phenomenon was Simmel who, in 1950, wrote of the overload of sensations in the urban world. Deutsch (1961) also noted that communication overload was a disease of cities and Meier (1963) predicted saturation in communications flow and crisis overload within the next half century. Much earlier, however, in 1755 Diderot, the French philosopher, had noted that 'the number of books will grow continually, and one can predict that a time will come when it will be almost as difficult to learn anything from books as from the direct study of the whole universe' (Diderot, in Baker, 1987, 85).

In a world increasingly dominated by computer mediated communication systems, it appears that the volume and pace of information can become overwhelming (Hiltz \& Turoff, 1985; Kerr \& Hiltz, 1982). Further studies have defined information overload and its impact. In 1990, for example, Meglio and Kleiner looked at ways of managing information overload including time management, communication and the idea that individuals can reduce information overload as they are part of the problem. Their research showed that users of information all contributed towards information overload and if mistakes were realised, a conscious effort could be made towards more effective communication. A decade later both Farhoomand and Drury (2002) and Kirsh (2000) demonstrated that information overload affected managers in organisations on a daily basis and could have dramatic effects within an organisation.

Although a considerable amount of research has been undertaken in the information overload field as well as some broad literature reviews there has been little published since early 2000 apart from the work of Edmunds and Morris (2000) and Hall and Walton (2004).

This paper begins by providing the research design that was used to create the information overload model and formula (Section 2). Section 3 reviews the literature and identifies and defines factors (Units) that contribute to not being overloaded by information, and being overloaded by information. Section 4 determines how these factors interrelate, which, enables the theory boundaries to be set as discussed in section five. The paper concludes by providing the information model and formula and discusses the contribution of this research and its limitations.

\section{Research Design}

Dubin's theory-building methodology $(1976 ; 1978)$ was chosen for this study, and concepts from this methodology with the positivism paradigm were used to develop the conceptual model of factors associated with information overload. Dubin's model addresses the 'paradox of embracing prior research while at the same time not being bound by it' (Holton \& Lowe, 2007).

Dubin's eight-step theory building methodology consists of two parts, conceptual development and research operation. This research focused on developing the conceptual model and providing a starting place for further research and debate. To do this, an interdisciplinary approach was used to compile a comprehensive list of factors. As a result data were collected from articles from various fields of study, such as psychology, computer science, information system management, marketing, organisational studies and accounting, as well as library and information science. The four steps followed in this study are part one of Dubin's method:

(1) Identification and definition of the units of the theory (Section 3 of this paper);

(2) Determination of the laws of interaction that state the relationships between the units of the theory (Section 4 of this paper);

(3) Definition of the boundaries of theory to help focus attention on forces that might impact the interplay of the units (Section 5 of this paper); and

(4) Definition of the theory's system states (Section 6 of this paper). 
The four steps of the second part of Dubin's methodology were not part of this research, but will be part of future research in taking the theory into a real world context to conduct empirical research.

\section{Identification and Definition of the Units of the Theory}

Before any conceptual model can be built it is important to understand the information overload landscape and identify the varied body of research into information overload across many different subjects. This provides an insight into the factors that need to be considered when developing the model. According to Butcher (1995) the research into information overload has focused on individuals, organisations and customers, with little overlap between the research groups:

A. Personal Information Overload - research into the ability of workers to make decisions and solve problems when confronted with large amounts of information. Recommendations to overcome such issues have been based on technological and behavioural solutions.

B. Organisational Information Overload - research is split into categories, one being based on too much paper and the other encompassing wider information systems including email and electronic document management. Solutions to the problems range from the introduction of new systems (behavioural or technological) to reduce the flow of information through intelligent agents.

C. Customer Information Overload - research into how it affects customer spending strategies.

Klausegger and Sinkovics (2007) categorise studies on information overload into Organisation Studies, Psychology and Marketing. Reflecting on the specific studies reviewed in their work, they map onto Butcher's work (1995). There is a direct link between Butcher's Organisational Information Overload and Klausegger and Sinkovics's Organisational Studies, between Butcher's Personal Information Overload and Klausegger and Sinkovics's Psychology (where Psychology is based around human behaviour and processing ability) and finally, between Butcher's Customer Information Overload and Klausegger and Sinkovics's Marketing, which focuses on consumers.

It could be argued that Butcher's categorisation of Customer Information Overload appears to be misplaced and that Customer Information Overload could be viewed as just a context for Personal Information Overload. 'Context', however, is a significant factor in information overload that needs to be modelled and has been shown to be important by a number of researchers including Allen and Shoard (2005) and Hall and Walton (2004). Another key factor that appears in the research into Customer Information Overload is 'strategy'. The information an individual receives within a specific context will determine the strategy or coping mechanisms they will use. This is partially viewed as an Adaptation Mechanism by Klausegger and Sinkovics (2007). The strategy adopted could be influenced by level of prior experiences, a point discussed in the next section on information overload factors.

The relationship between Personal Information Overload (individuals) and Organisational Information Overload is an intrinsic one. An organisation is made up of more than one individual who contributes to the addition of information, and iteratively updates and retrieves from the organisation's information sources as shown by the authors' model in Figure 1. It is important that the link between the two is factored into any model of information overload, whereby the individuals of the organisation contribute to the ongoing collection of information stores. The sum (organisation), however, is greater than its parts (individuals) as shown by specific studies surrounding organisation structure and the impact of information processing and capacity (Buchanan, Claydon, \& Doyle, 1999; Cukrowski \& Baniak, 1999; Schultz \& Vandenbosch, 1998; 
Sparrow, 1998). The specific structures and the influence will not be modelled explicitly in this paper, as the level of detail would make the model too complex, but future research will aim to provide a finer level of granularity. A detailed review of the organisational studies can be found in Klausegger and Sinkovics's review of information overload (2007). The next step of this research is to identify the factors that affect the individual processing information and that lead to information overload.

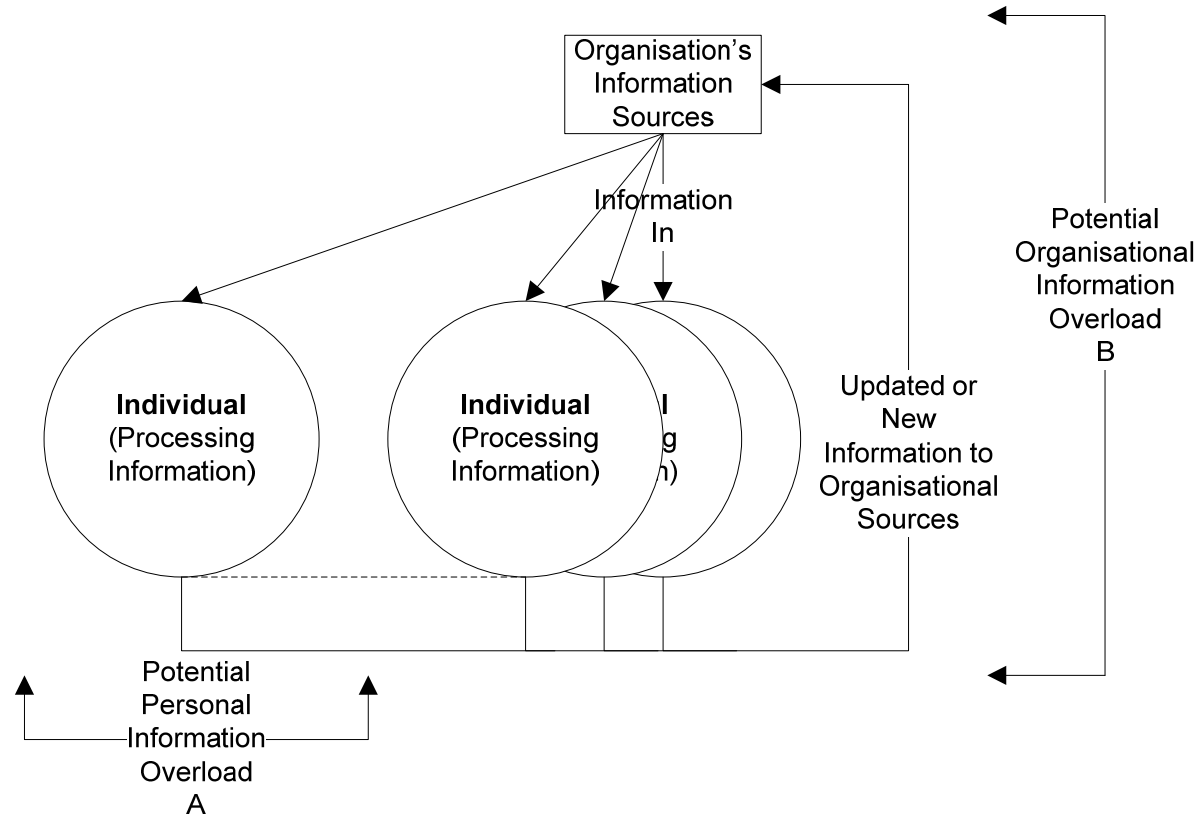

Figure 1 - The impact an individual has on information overload within an organisation and vice versa

\subsection{Factors of the Information Overload Landscape}

Defining information overload has been attempted by a number of researchers, each with their own interpretation, but all having very common themes that can potentially be used as factors in developing the information overload model. A few example definitions are provided below.

- 'Information overload can occur when the information processing demand on an individual's time for performing interactions and internal calculations exceeds the supply or capacity of time available for such processing' (Schick, Gordon, \& Haka, 1990).

- 'Information overload is the state of an individual (or system) in which not all communication inputs can be processed and utilized, leading to breakdown' (Jones, Ravid, \& Rafaeli, 2004).

- 'Information overload is the inability to extract needed knowledge from an immense quantity of information for one of many reasons' (Nelson, 1994).

- 'At the personal level, we can define information overload as: a perception on the part of the individual or observers of that person, that the flow of information associated with work tasks is greater than can be managed effectively, and a perception that overload in this sense creates a degree of stress for which his or her coping strategies are ineffective' (Wilson, 2001). 
These definitions highlight the high level factors of information overload which also fall into the categories of intrinsic and extraneous factors, an approach derived from Eppler and Mengis (2004), in which the relationship between causes and fundamental variables are analysed.

Intrinsic factors are fundamental elements of the information overload problem and directly influence information overload. Eppler and Mengis showed that the Information Processing requirement and an individual's Information Processing Capacity were intrinsic factors of information overload. In addition, time constraints can also be seen as an essential component (Schick et al., 1990).

Extraneous factors indirectly contribute to information overload and have a direct effect on intrinsic factors. Both extraneous and intrinsic factors are also known as overload causes (Eppler \& Mengis, 2004). Eppler and Mengis presented information overload causes in five categories: Information Characteristics, Task and the Process Parameters, Personal Factors, Organisational Design and Information Technology. Kirsh (2000) determined four causes: too much information supply, too much information demand, the need to deal with multi-tasking and interruption, and inadequate workplace infrastructure. Two problems, however, can be found in Kirsh's study. Firstly, there is no differentiation between intrinsic and extraneous factors; information supply and information demand are fundamental factors of the information overload problem. Secondly Kirsh's determination of causes proposes a restricted view of important factors, when each of them could be a sub-category of causes as determined by Eppler and Mengis. Farhoomand and Drury's findings (2002) are similar to those of Kirsh in that they noted volume of information, time constraint, noise and channel as components of information overload based on a survey conducted on 124 managers.

In this paper, the extraneous factors are identified and their influences on intrinsic factors are defined. Some factors, however, such as organisational design, which is also noted in the literature, have not been modelled in this paper, but will be added in future research. Extraneous factors discussed in this paper are the Characteristics of Information, Quality of Information, Task and the Process Parameters, Personal Factors, and Sources of Information. The main information overload factors detailed in the literature review are shown in Table 1 and a description of these factors is provided in the following sections.

\begin{tabular}{|c|c|}
\hline Information overload factor & Reference \\
\hline \multicolumn{2}{|l|}{ Intrinsic Factors } \\
\hline $\begin{array}{l}\text { Quantity of Information: } \\
\text { - Amount of information available } \\
\text { - Information processing requirement }\end{array}$ & $\begin{array}{l}\text { (Hiltz \& Turoff, 1985; Miller, 1994; Nelson, 1994) } \\
\text { (Eppler \& Mengis, 2004; Tushman \& Nadler, 1978) }\end{array}$ \\
\hline Information Processing Capacity & $\begin{array}{l}\text { (Cooper, 1998; Heylighen, 2002; Miller, 1960; Newell } \\
\text { \& Simon, 1972; Shannon, 1948) }\end{array}$ \\
\hline Available Time & (Schick et al., 1990) \\
\hline Extraneous factors & \\
\hline Characteristics of Information: & \\
\hline
\end{tabular}




\begin{tabular}{|c|c|}
\hline $\begin{array}{l}\text { - } \text { Complexity of information } \\
\text { - } \text { Ambiguity of information } \\
\text { - Uncertainty of information } \\
\text { - } \quad \text { Novelty of information }\end{array}$ & $\begin{array}{l}\text { (Plumlee, 2003; Schneider, 1987) } \\
\text { (Schneider, 1987) } \\
\text { (Schneider, 1987) } \\
\text { (Keller \& Staelin, 1987; Schneider, 1987) }\end{array}$ \\
\hline $\begin{aligned} & \text { Quality of Information: } \\
&$\[ \quad \text { Information usefulness } \]$ \\
& 0 \text { Relevance } \\
& 0 \text { Validity } \\
&\end{aligned}$ & (Slawson, Shaughnessy, \& Bennett, 1994) \\
\hline $\begin{array}{l}\text { Task and the Process Parameters: } \\
\text { - } \text { Task complexity } \\
\text { - } \text { Task novelty } \\
\text { - Task interruption } \\
\text { - } \text { Multi-tasking }\end{array}$ & $\begin{array}{l}\text { (Bawden, 2001) } \\
\text { (Tushman \& Nadler, 1978) } \\
\text { (Speier, Valacich, \& Vessey, 1999) } \\
\text { (Wurman, Leifer, Sume, \& Whitehouse, 2001) }\end{array}$ \\
\hline $\begin{array}{l}\text { Personal Factors: } \\
\text { - } \text { Level of prior experiences } \\
\text { - } \text { Personal skills } \\
\text { - } \text { Cognitive style } \\
\text { - } \text { Motivation of the person } \\
\text { - Personal situation }\end{array}$ & $\begin{array}{l}\text { (Swain \& Haka, 2000) } \\
\text { (Owen, 1992); } \\
\text { (Sewall, 1988) } \\
\text { (Muller, 1984) } \\
\text { (O'Reilly, 1980) }\end{array}$ \\
\hline Intrinsic \& Extraneous Factor & \\
\hline $\begin{array}{l}\text { Sources of Information: } \\
\text { - Push versus Pull }\end{array}$ & $\begin{array}{l}\text { (Edmunds \& Morris, 2000; Herther, 1998; Kirsh, 2000; } \\
\text { Speier et al., 1999; Wilson, 2001) }\end{array}$ \\
\hline
\end{tabular}

Table 1: Factors associated with information overload

\subsection{Intrinsic Factors}

\subsubsection{Quantity of Information}

Quantity of Information is described in different ways in the literature, such as, information available, information processing requirement or information supply. The Quantity of Information available is the total amount of information which exists and is accessible for the individual on a specific topic (Hiltz \& Turoff, 1985; Miller, 1994; Nelson, 1994). The term 'available information' has been mostly used in the marketing and social science discipline (Miller, 1994; Nelson, 1994). The information processing requirement refers to the Quantity of Information that needs to be processed in a limited time frame (Tushman \& Nadler, 1978). The Quantity of Information is the traditional source of information overload (Tushman \& Nadler, 1978). Overabundance of information available, supply or requested is known as the most important factor by which information overload problem is likely to happen (Galbraith, 1974; Nelson, 1994; Tushman \& Nadler, 1978). The volume of information has a direct impact on information overload, which means the more information available the higher the probability of information overload occurring (Nelson, 1994).

\subsubsection{Information Processing Capacity}

Information Processing Capacity refers to the Processing Capacity of the individual which is limited by the storage capacity and processing limitations of the human brain (Heylighen 2002). The mind is 
divided into three segments (Cooper, 1998): sensory memory, by which stimuli is received from the senses such as sight, and sounds; Working memory, which is most active in solving problems, making decisions, organising, calculating and creating ideas (Zull, 2002); and Long term memory, which holds a permanent and massive body of knowledge and skills.

Earlier research shows that people have clear limits in the amount of information they can process (Cooper, 1998; Miller, 1960; Newell \& Simon, 1972). Miller (1960) has shown that a person can only keep a few (about seven on average) isolated items at once in their working memory. This indicates that there are clear limits on the speed with which the brain can process items in working memory (Heylighen, 2002). The Information Processing Capacity concept comes from Miller's work (1994) and has been defined in two ways by scholars based on their perceptions in defining the overload problem. Either it refers to 'the time it takes an individual or system to seek, filter and extract the required information' (Jackson, 2011), or 'the quantity of information one can integrate into the decision making process within a specific time period' (Eppler \& Mengis, 2004). It is likely that a person with a higher Information Processing Capacity can cope with more information (Miller, 1994) and the higher the Information Processing Capacity of an individual, the less likely the probability of information overload.

\subsubsection{Available Time}

This factor was reinforced by Schick et al. (1990) in their definition as 'capacity of time available' and was considered as an intrinsic factor due to its direct effect on information overload. Allowing more time for task performance can decrease the likelihood of information overload.

\subsection{Extraneous Factors}

\subsubsection{Characteristics of Information}

Schneider (1987) distinguishes various information characteristics, such as the level of complexity associated with information and level of ambiguity, novelty, intensity or uncertainty. There are other factors such as diversity of information (Bawden, 2001), and information duplication which could also be characterised as a qualitative factor. Information attributes (e.g. complexity, uncertainty and ambiguity) have a direct correlation with Information Processing Capacity (Jackson, 2011) and it is possible that specific information which is complex for one person will not be complex for another because of the individual's cognitive capacity. Consequently, not only the amount of information but also Characteristics of Information influence information overload (Iselin, 1993; Keller \& Staelin, 1987; Owen, 1992; Schneider, 1987).

\subsubsection{Quality of Information}

Information Quality is the degree to which information meets the needs of its users (Stvilia et al. 2005) and is difficult to observe, capture or measure. Information quality dimensions are the means by which we can measure the Quality of Information (Redman, 1997). Quality of information can influence an individual's Information Processing Capacity since individuals can use high-quality information quicker and better than ill-structured or unclear information (Schneider, 1987). Poor Quality of Information can lead to a paradox that when too much information is being received there is not enough of the right information (Katzer and Fletcher 1992). Keller and Staelin (1987) stressed overall Quality of Information as usefulness of information, a quality later defined by Slawson et al. (1994) as being based on validity and relevance of information. As Edmunds and Morris (2000) stated, it was often difficult to find useful and relevant information. Ackoff (1967) noted that the abundance of irrelevant information led to information overload, while Simpson and Prusak (1995) considered lack of quality information as the main cause of information overload. Kirsh (2000) 
showed that there was an exponential growth in amount of information, but assumed only linear growth in the quantity of quality information.

\subsubsection{Task and the Process Parameters}

Various factors related to task and the process that needs to be completed are identified in the literature. This group of factors involves task novelty (Tushman \& Nadler, 1978), task complexity (Bawden, 2001), multi-tasking (Wurman et al., 2001) and task interruption (Speier et al., 1999). According to Campbell (1988), to determine task complexity relevant characteristics of a task should be specified such as the number of alternative actions, multiple conflicting goals and uncertainty of actions. These parameters have negative consequences on intrinsic factors. A novel and complex task increases information processing requirements, and time pressure (Schick et al., 1990), and task interruption and multitasking can decrease Information Processing Capacity (Wurman et al., 2001).

\subsubsection{Personal Factors}

Personal Factors involve level of prior experiences (Swain \& Haka, 2000). These include experience in the field and experience of producing results for the particular tasks (Jackson, 2011), personal skills (Owen, 1992) such as reading and analysing speeds (Jackson, 2011) and cognitive style, with the preferred ways of gathering, organizing, analysing, or recalling information and experience (Sewall, 1988). Other factors that are used to determine information overload subjectively include motivation of the person (Muller, 1984) and personal situation (O'Reilly, 1980).

\subsection{Intrinsic and Extraneous Factors}

\subsubsection{Sources of Information}

Sources of information can influence both intrinsic and extraneous factors. Nowadays, an individual or system receives information from either pulling information, or being pushed information.

Pushed information is information that the recipient has little control over, and pulled information is information that is on demand and can be searched for and used when required by the recipient (Kirsh, 2000). Wilson (2001) stated that pulled information is related to what researchers have called the 'need for cognition', this need being the extent to which people feel they need information and therefore seek that information in order to understand it. Although many organisations have withdrawn push technology in favour of information pull this does not prevent people acting as pushers of information. Whenever people send a document, electronically or otherwise, they are pushing information and although this may not form a problem when performed on a need to know basis, there is of course the potential to cause disruption (Wilson, 2001). When push technology was relatively new, Herther (1998) suggested that the benefits were that it allowed for regular canvassing of selected information sources for new information whilst an individual was working on another application. Although pushed information reduces information retrieval time it nevertheless increases the amount of useless information (Edmunds \& Morris, 2000) and causes more frequent interruptions (Speier et al., 1999).

There is a variety of information sources available to people, some that they have little control over (pushed information), some they have greater control over (pulled) and some that are in the middle of the spectrum as they can either be pulled or pushed. This is shown by Figure 2, which provides examples of information sources on the information spectrum.

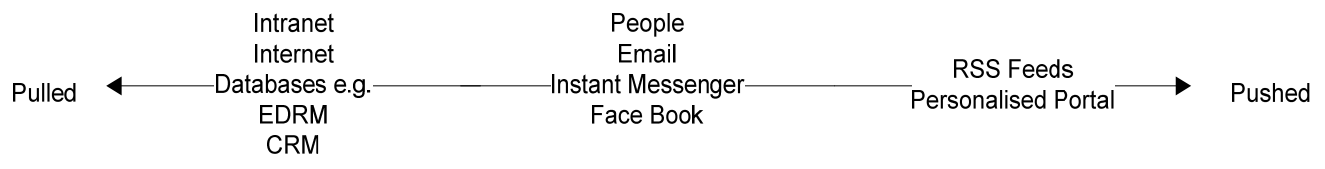




\section{Interacting Units of the Model}

The basic building blocks involved in information overload that occur in the individual landscape are information, individual, and task. The theories about information overload are mainly built upon characteristics of those units, such as the amount of information, information processing capacity and time constraints. Dubin (1978) referred to these types of units as 'enumerative'. In this research, all factors associated with information overload, from intrinsic to extraneous, were considered as enumerative units by which the information overload phenomena could be illustrated, and information overload itself was considered as an event that may appear based on the value of the contributor units. The seven units that form the information overload model are:

- Unit 1: Quantity of Information - is the total amount of information which exists and is accessible to the individual on a specific topic (Hiltz \& Turoff, 1985; Miller, 1994; Nelson, 1994).

- Unit 2: Characteristics of Information - consist of factors related to information characteristics including complexity, ambiguity, uncertainty and novelty (Schneider, 1987). These factors have a relationship with the Information Processing Capacity (Unit 4) because the time it takes to process the information will depend on the complexity, ambiguity, uncertainty and novelty of information against an individual's Information Processing Capacity. These combined components are then affected by Personal Factors and in particular the knowledge an individual can draw upon to process the information (Unit 7).

- Unit 3: Quality of Information - is made up of two factors combining relevancy and validity of information (Slawson et al., 1994). There is a direct relationship between relevancy and validity of information and the Quantity of Information available (Unit 1). For example, the less relevant and more valid the information is will be compounded by the large quantities of information, which means greater Information Processing Capacity and Available Time is required to sift through the less relevant information.

- Unit 4: Information Processing Capacity - is referred to as 'the quantity of information one can integrate into the decision making process' (Eppler \& Mengis, 2004). Information Processing Capacity is affected by Personal Factors, such as, experience, personal skills and cognitive style. This previous knowledge can be drawn upon to aid in the processing of information. It is the speed, however, at which an individual can process new information, retrieve and utilise existing knowledge (Unit 7) that ultimately determines the Information Processing Capacity of an individual.

- Unit 5: Available Time - can be described as the 'capacity of time available' (Schick et al., 1990) for the individual to complete a specific task or process.

- Unit 6: Task and the Process Parameters are made up of multiple factors combining task novelty and task complexity. Relevant characteristics in determining task complexity are the number of alternative actions, multiple and/or conflicting goals, and uncertainty goals (Campbell, 1988). It also includes Task Interruption which is 'an externally generated, randomly occurring, discrete event that breaks the continuity of cognitive focus on a primary task' (Corragio, 1990). In this study, interruption is assumed as one of the properties of a task that can contribute to information overload occurring. 
- Unit 7: Personal Factors are made up of multiple factors combining level of prior experiences, personal skills, cognitive style, motivation of the person, and personal situation. Personal Factors directly affect the Information Processing Capacity (Eppler \& Mengis, 2004). These factors cannot be entirely distinguished from Information Processing Capacity, since the knowledge is essentially acquired over time and contributes to the degree of Information Processing Capacity. In addition to the individual knowledge, the individuals' current situation will affect their processing capacity in relation to their motivation to complete a task and their personal situation which for example, could be related to 'happiness at work' and to events happening outside of work.

Tipping Point - is the point at which information overload occurs. It is the critical point of the presented model by which the model is lead from one state to another, overloaded or notoverloaded.

Each unit has its own individual contribution to information overload, which means an increase in scope of one unit can increase or decrease the likelihood of information overload happening. As a result, units can be divided into two groupings: 'For' factors, which increase the likelihood of information overload occurring, and 'Against' factors, which when increased, lessen the possibility of information overload. In addition the classification of the units, shown by Figure 3, was also determined by how they could counterbalance each other. An example of counterbalancing units is Characteristics of Information (For) and Personal Factors (Against). As noted in the units section above, the combined components of Characteristics of Information are affected by Personal Factors. For example, a low level of individual knowledge on a specific task given high novelty and complexity will have a negative effect on information overload. It could be argued, however, that these two units could swap sides within the model and it would have little effect on the overall outcome of the model because they counterbalance each other. The success of the model depends on the units being placed on the correct side of the model providing appropriate counterbalance and ensuring the weightings assigned to each unit are appropriate, as discussed in section 6.2. An example of how the units can be 'For' or 'Against', is demonstrated by an increase in the Available Time or Individual Information Processing, which can decrease the likelihood of overload occurring. These two units (For) provide more time to complete the task, as an increased processing speed can enable the information to be processed quicker than with someone with a slower processing capacity. Another example which also takes into account counterbalancing is if the Quantity of Information (Against) increases and the Available Time and the Information Processing Capacity do not increase, the possibility of information overload occurring will increase.

The 'For' and 'Against' categories can be used as the law of interaction, which can both be identified as Dubin's categoric type of law (Dubin, 1978).

Law 1: Information Processing Capacity, Characteristics of Information and Available Time, cooperate with each other to decrease the probability of information overload occurrence.

Law 2: Quantity of Information, Quality of Information, Task and the Process Parameters, and Personal Factors cooperate with each other to increase the probability of information overload occurrence. 


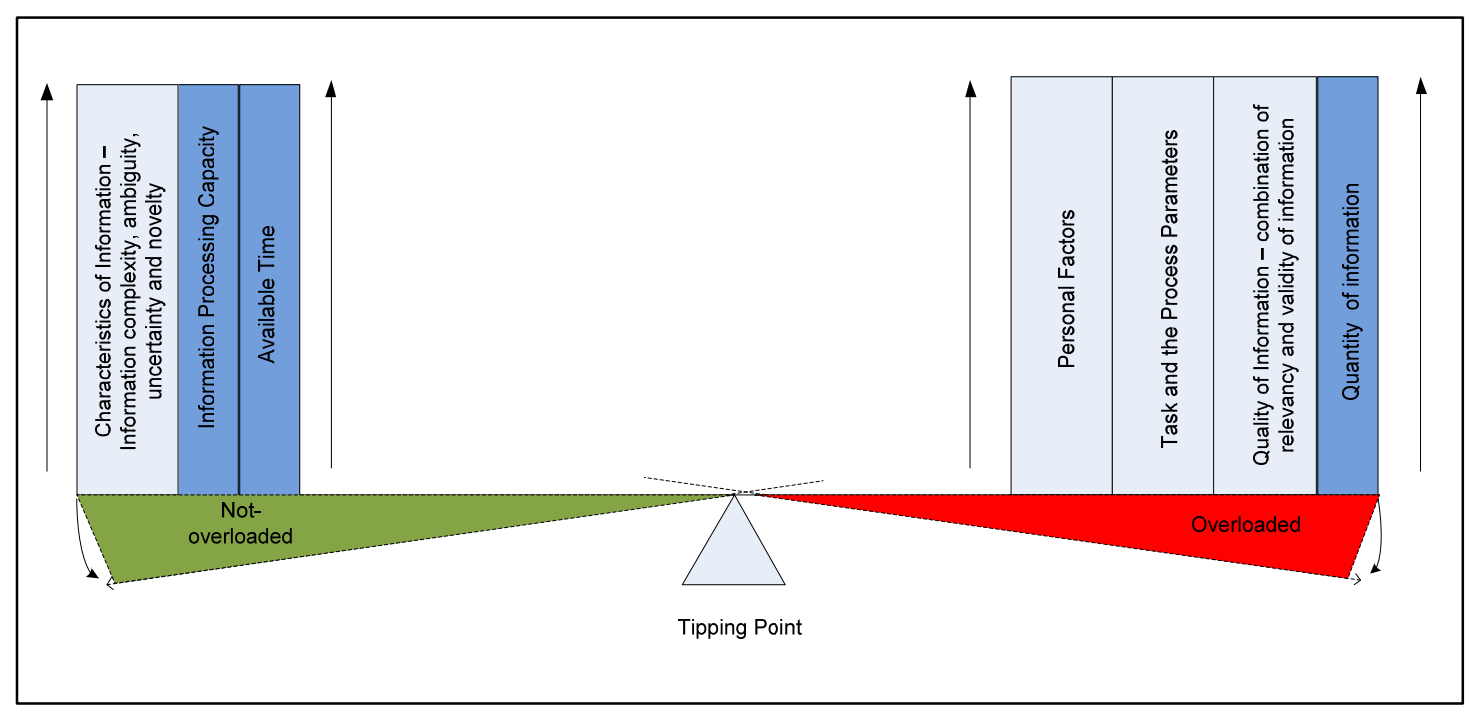

Individual boundary

Figure 3 - The conceptual information overload model

\section{Theory Boundaries}

In this research information overload was determined in the individual landscape. As a result the conceptual model is also constructed in the individual domain which was considered to be Dubin's boundary due to the interdisciplinary approach of the study (Dubin, 1978). However, as discussed earlier, in organisational studies there is an inherent relationship between personal and organisational information overload as was shown in Figure 1. In organisational studies, the individual domain is an open boundary, because it can be exchanged with the organisation if the boundary becomes extended.

This section of the paper presents the system states of the theory. Three criteria must be met in a theoretical model in order for a system state to exist. These three criteria, inclusiveness, determinate values, and persistence are used to determine the system state's existence as well as to define the system state (Dubin, 1978). The inclusiveness criterion states that all of the units within the system have a distinct value, or range of values, when the theoretical model is in that system state. The determinate values criterion states that the values of all the units in the model may be measured, at least in principle, by instruments that give true values. Finally, the persistence criterion indicates that the system state must persist through some period of time. These system states 'represent conditions of the theoretical model in which the units of the theory interact differently' (Lynham, 2000). In this research, two system states were specified for the model, namely, overloaded and not-overloaded. These system states are activated by the change in the value of the units. Based on Dubin's inclusiveness criterion, each of the units in the 'information overload factors model' is collaborated and has a specific value in both system states and they can all be measured (meeting the determinate values criterion) and this can only happen over a period of time (meeting the persistence criterion) (Dubin, 1978).

Not-Overloaded: The first system state specified for the proposed model is 'not-overloaded', which is a state where an individual can handle the Quantity of Information that they are required to process. This system state continues to a transition point that earlier in this paper was identified as the tipping point. The tipping point is actually the point at which the system state changes from 'notoverloaded' to 'overloaded'. 
Overloaded: The second system state specified for the proposed model is 'overloaded', which is a state where the individual cannot handle the Quantity of Information that they receive and becomes overloaded by information.

\section{The Information Overload Model and Formula}

As a result of the conceptual development the components of the conceptual model are: the model units; laws of interaction between units; boundaries of the system and the system states. By using all of these components it is possible to model the factors associated with information overload, shown by Figure 3. In the model, the tipping point is the centre of the system and 'For' factors have been placed on the right side and the 'Against' factors on the left side. The blocks related to intrinsic factors are filled with a darker colour compared with the extraneous factors. The territory of each state of the model is coloured differently. If overall weighting on the right side of the model ('Against' factors) is more than the overall weighting of the left side ('For' factors), the individual or system will be in an 'overloaded' state, and as a result becomes overloaded by the amount of information. Contrastingly, if the overall weighting of the right side is equal or less than the left side of the model, the system is in the 'not-overloaded' state, and thus the individual or system can cope with the amount of information that needs to be processed. The next sections look at determining an information overload formula that could be used to determine information overload.

\subsection{Weightings}

The weightings for the model shown in Figure 4 still need to be determined and substantial research will have to be undertaken in order to establish them. The complexity of the research into determining the weightings can be illustrated by taking Information Processing Capacity as an example. Providing weightings for a system (computer) rather than an individual is potentially easier as many of the factors have already been determined. For example, the speed at which a system can process data is related to the clock speed of the machine, bits per second processing time which is dependent on variables such as cache and the instruction set used. The other elements to consider are the value of information that is being processed and determining what the result should look like. Shannon's work (1948) could help determine these factors, as Shannon's source coding theorem, which establishes that, on average, the number of bits needed to represent the result of an uncertain event is given by its entropy. Shannon's entropy can be used as a measure of the average information content that is missing when one does not know the value of the random variable. In addition to this Shannon's noisy-channel coding theorem could be used to cancel out the noise or unreliable information (unwanted information) provided that the rate of communication is below a certain threshold, called the channel capacity. By bringing all these elements together one could potentially determine the Information Processing Capacity of a system and therefore determine a weighting system. If trying to determine the Information Processing Capacity weighting for an individual, similar factors have to be measured such as experience in the field, experience of producing results for the particular tasks, speed of reading, speed of analysing, and speed of learning on the job; if one has to undertake a new task it might involve learning new skills to analyse information. Measuring these factors, however, is potentially much harder. 


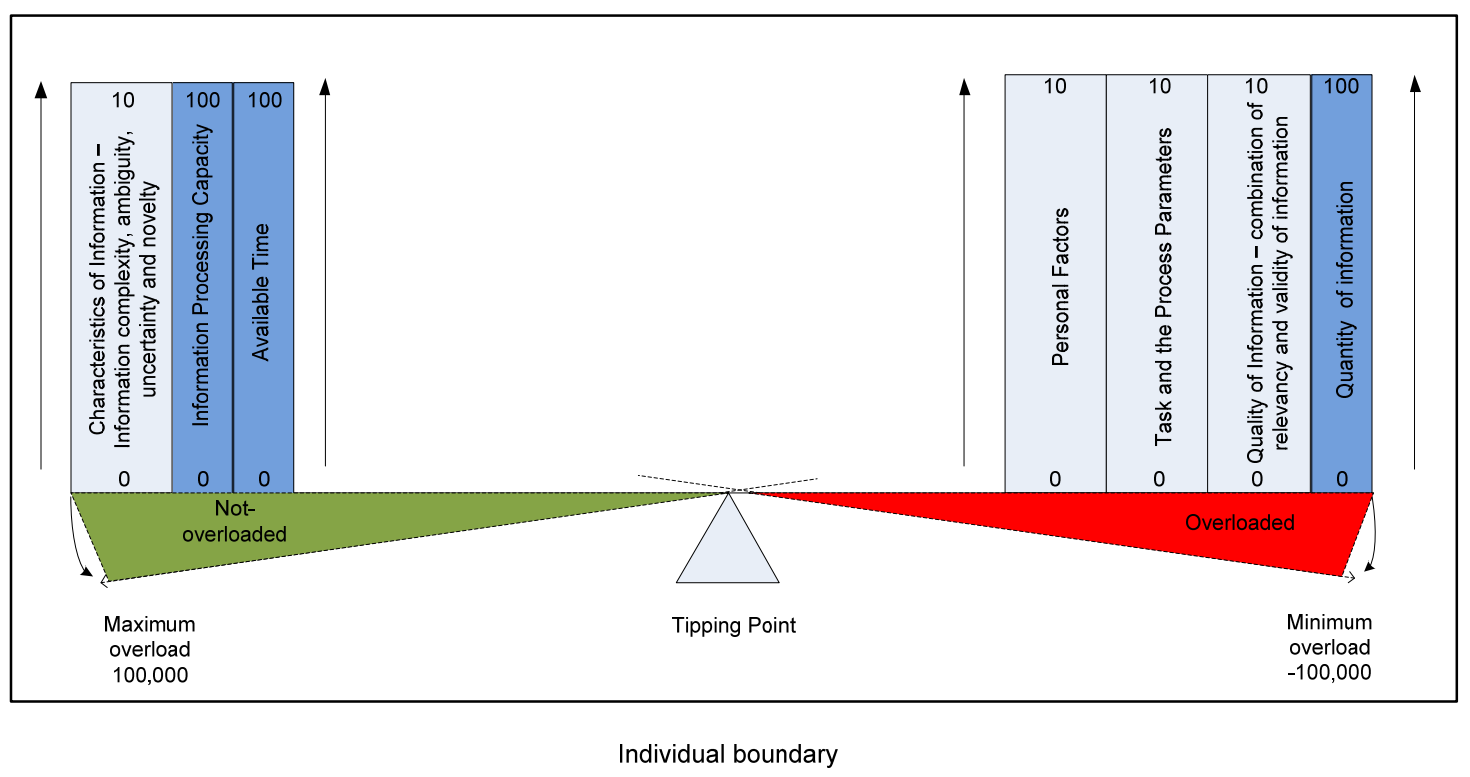

Figure 4 -Weighted Factors for Information Overload

While allocating arbitrary weighting to the factors, as shown by Figure 4, it was assumed that actual weightings would follow the same correlation between intrinsic and extraneous factors. The current weighting division shows the importance of intrinsic factors over extraneous ones. Weighting variation for intrinsic factors is between 0 and 100, but the variation for extraneous factors is between 0 and 10. In this form of weighting division, both sides of the given model and both fractions of the formula share the same overall weighting.

Based on the awarded weightings, if the model is in balance, both sides of the formula will present the same result, and the final result of the equation will be zero. That is to say, according to the formula (discussed in the next section) and based on current weighting, the balanced tipping point is equal to zero. The maximum result is equal to 100000 and minimum is equal to minus 100000 . Therefore, the amount of information which is overloaded fits in this arbitrary scope. Any result less than zero means the person is overloaded by information and a score greater than zero refers to a state whereby the individual has control over the problem.

\subsection{Information Overload Formula - Lowest Components}

By modelling factors that contribute to information overload in terms of their level of contribution and way of interaction, information overload could potentially be measured. Units from which the formula is constructed are the same as those established for the conceptual model, excluding the tipping point. As a result of this, the units which the formula is constructed from are: (1) Quantity of Information, (2) Characteristics of Information, (3) Quality of Information, (4) Information Processing Capacity, (5) Available Time, (6) Task and the Process Parameters, and (7) Personal Factors. Four of the identified units are considered as multi-factored in nature and can be broken down to show the low level attributes:

- Characteristics of Information (2),

- Quality of Information (3),

- Task and the Process Parameters (6),

- Personal Factors (7).

The components of these four units 2, 3, 6, and 7, have been detailed below. 
Characteristics of Information: consists of complexity, ambiguity, uncertainty and novelty (Schneider, 1987). Each of these components has a direct impact on the Characteristics of Information which can lead to overload, and this unit is calculated by multiplying the components. The less complex, ambiguous, uncertain and novel the information the higher the score given to these components, as individuals can process information quicker and better than ill-structured or unclear information (Schneider, 1987). However, for example, more complex information could be deemed as higher-quality but will receive a lower component score because the complexity of the information is likely to take more time to process. This is taken into account by multiplying this unit against both Information Processing Capacity and Available Time to provide a 'not-overloaded' score against a combined 'overloaded' score. Just taking complexity for example, if a piece of information is quite complex it could be awarded a two out of ten, and if it is not that complex an eight. This score would then be multiplied against Information Processing Capacity of say 80 . The less complex information would provide a score of 640 and the more complex 160 which would then have to be offset by the overloaded calculations. This demonstrates that this formula has not penalised the information for being complex and potentially higher quality, but has shown it might take longer to process which ultimately might be quicker to process than quantities of less complex information.

$$
\text { Characteristics of Information }=\text { Complexity } \times \text { Ambiguity } \times \text { Uncertainty } \times \text { Novelty }
$$

Quality of Information: in accordance with Slawson et al. (1994), it can be measured by multiplying validity by relevancy which both have a compound impact on the Quantity of Information. The lower the validity and relevance of the information the higher the score awarded for this unit in the formula. The arbitrary range of values that can be attributed to Validity is from 0 to 1 , and for Relevancy 0 to 10 . An overall score of 10 would indicate little Validity and little Relevancy.

$$
\text { Quality of Information }=\text { Validity } \times \text { Relevancy }
$$

Task and the Process Parameters consist of task novelty and task complexity. These, therefore, can be calculated by multiplying task complexity by task novelty plus the number of task interruptions and the number of other tasks being worked on (multi-tasking). Multi-tasking could be part of the Available Time factor, but it has been kept as a separate element to draw attention to the negative affect both multi-tasking and task interruptions can have on a task, as highlighted by Jackson (2009) and Jackson \& Lichtenstein (2011). The more complex the task and process required will result in a high score being assigned to this unit in the information overload formula. The arbitrary value range assigned to the components are: Task Complexity 0 to 2; Task Novelty 0 to 2; Task Interruptions is shown as 1 for every 20 interruptions and the range is 0.0 to 4.0; and Other Tasks 0.0 to 3.0, where a major task is assigned a 1, with a maximum of 3 major tasks being assigned during the task period.

Task and Process $=$

Task Complexity + Task Novelty + Number of Task Interruption + Number of other Tasks (MultiTasking)

Personal Factors are made up of multiple components combining level of prior experiences, personal skills, cognitive style, motivation of the person, and personal situation. The less experience and motivation a person has will reflect in a higher score in the information overload formula. Each component can score a maximum of 2 (the worst case scenario). An overall score of 10 would indicate poor Personal Factors, where completing the task would take longer. 
As mentioned, the formula was constructed on the same basis as the model, and is shown by Formula1. The units were placed in the formula based on their negative or positive influence on information overload. The developed formula consists of two sides of factors, by which information overload can be calculated upon their subtraction.

Information Overload $=$

(Characteristics of Information x Information Processing Capacity x Available Time) -

(Personal Factors x Task and the Process Parameters x Quality of Information x Quantity of Information)

\section{Formula 1 - Information Overload Formula}

The first side of the subtraction involves Information Processing Capacity and Available Time as the intrinsic factors and Characteristics of Information as the extraneous factor including, information complexity, ambiguity, uncertainty and novelty. The reason for placing the Characteristics of Information on the 'not-overloaded' side is the direct influence it has on the Information Processing Capacity and Available Time. For example, given less complex information, little ambiguity, small amounts of uncertainty, and if the person has worked with similar information before (novelty), then less processing capacity and time are required to complete the task. However, if the opposite occurs or differing variations, then there is a likelihood that the factors that the person has little immediate control over will not be sufficient enough (e.g. Information Processing Capacity) to complete the task without being overloaded, thus requiring a balancing act within the first side of the subtraction which is offset against the second side of the subtraction to avoid information overload.

The second side of the subtraction consists of four factors of which one is intrinsic - Quantity of Information - and the other three are extraneous factors. As noted in the literature, the Quantity of Information influences Task and the Process Parameters. For example, a more complex task may require more information to process it (Schick et al., 1990). The first extraneous factor is Personal Factors, the second is Task and the Process Parameters, and the third the Quality of Information including relevancy and validity. The factors, like the first side of the subtraction, interrelate and can also be offset against the other side of the subtraction. For example, the task interruption part of the Tasks and Process Parameters has a negative impact on Information Processing Capacity of an individual (Wurman, 2001). The relevant and valid information part of Quality of Information reduces processing time and reduces the Available Time required (Schneider, 1987). The Personal Factors, like the speed of reading and previous experience, directly affect the Information Processing Capacity and have been influenced by the environment in which the individual lives and works. In accordance with the propositions of the theory, the result of the formula will indicate that the individual is 'overloaded' by information if the overall weighting of the 'For' factors is more than the overall weighting of the 'Against' factors.

\subsection{Example of Calculating Information Overload}

Although arbitrary weightings have been used, an example scenario of how the formula can be used to determine information overload might be useful for further research into determining the measurements. The factors the task affects have been denoted by brackets and an arbitrary weighting provided. An employee has to submit a ten page report about a new project to a supervisor within a week (Available Time [27]). The task itself is a routine report which is neither new nor complex. Considering the environment that the individual works in, interruption is high due to the frequency of communication between colleagues during the day as well as other factors such as push technology by which interruption is increased (Task and the Process Parameters [4]). The Task and the Process Parameters have been calculated by awarding Task Complexity (1) + Task Novelty (1) + Task Interruptions (which is likely to be 20 , but shown as 1 for every 20) (1) + (1) Other 
Task that has to be completed within the week. The higher the number awarded for Task and the Process Parameters the harder it is to complete the task.

There is a substantial volume of information available on the internet, from library and other accessible sources, as well as previously gathered information by the individual (Quantity of Information [70]). However, quite a bit of the information available is valid but not relevant to the report (Quality of Information [6]). Quality of Information has been calculated by determining the validity of information (0.6) multiplied by the relevance of the information (10).

The attribute of the information also varies from basic and easy-to-understand documents to papers which contain complex mathematical equations (Characteristics of Information [6]). Unit 2 has been calculated by determining the complexity of the information which is quite high (12) multiplied against how ambiguous it is (2) multiplied by the uncertainty ( 0.5$)$ and the novelty of the information to the employee (0.5).

Given the previous experience of the individual, Information Processing Capacity is about average (Information Processing Capacity [52]). As the employee is international and whose first language is not English, language barriers influence the speed and accuracy of reading and writing skills in spite of the employee having gained sufficient prior knowledge in the field in the last few years (Personal Factors [5]). This is calculated by determining the level of prior experience (1.5) added to their personal skill set (0.5) added to their cognitive style of working (0.5), added to their motivation to complete the work (0.5), added to their personal situation and wellbeing and in this case the employee has just split up with their partner which is affecting their work performance (2). The higher the overall score indicates a deficiency in personal attributes to complete the task within a reasonable amount of time.

The result of the scenario, 24, fits on the arbitrary scale approved, but it is really close to the tipping point, zero. Therefore with any change in the factors, for example an unpredicted interruption, the individual can be 'overloaded' by the information.

$$
\text { Information Overload }(24)=(6 \times 52 \times 27)-(5 \times 4 \times 6 \times 70)
$$

\section{Conclusion}

The concept of information overload is referred to in a variety of ways, depending on the perspective context in which it is experienced. Researchers from different fields have identified the factors which contribute to information overload based on their interpretation of the problem such as psychology, information system management, computer science, marketing, organisational studies and accounting. As a result of this, key definitions, situations and fundamental components of the overload problem were derived from various fields of study. Research to date has either added to these factors or collated the existing factors, but not attempted to analyse them to create interrelating attributes of information overload.

This research has gathered the fundamental elements that contribute to information overload to develop a new theory-based model of factors affecting information overload and providing a formula for calculation of the extent of the overload, to aid in visualising the complex issues. The research has been constructive in nature, and due to this approach, it makes several contributions to the current literature. Two methods for categorising factors that contribute to the overload phenomena were introduced in this research. The first method separates those factors based on their direct or indirect effect on information overload called intrinsic and extraneous factors respectively. The second method divides factors based on whether or not the factor increases or decreases information overload likelihood and tags those factors in terms of 'For' or 'Against'. These 
new methods for categorisation not only assisted in the development of the conceptual model and in creating the formula, but could be used in other aspects of information overload research, such as finding and evaluating the countermeasures to information overload.

The value of building a new theory-based model of factors affecting information overload and providing a formula for calculation of the extent of the overload could be realised in many different areas connected with information management where a diagnostic tool to measure current environment and any future inventions made is required. For example:

- Measuring the benefits of modifying or developing new systems, that aid employees in storing information effectively and efficiently for future retrieval

- A diagnostic tool supporting individual or organisation development, which would highlight specific employee skills for development

- An aid in scheduling an employee's workload to optimise efficiency and the quality of work produced.

The theory-based model of factors affecting information overload and the formula developed for calculation of the extent of the overload provide a significant contribution to the information overload body of research, but future research will need to be undertaken to determine the values and accuracy of the model in a 'real-life' context.

\section{Acknowledgements}

This research was supported by Loughborough University. We thank the reviewers for their valuable comments and advice.

\section{References}

Ackoff, R. L. (1967). Management misinformation systems. Management Science, 14(4), B-147-156. doi: 10.1287/mnsc.14.4.B147

Baker, K.M. (Ed.) (1987) The Old Regime and the French Revolution. Chicago: University of Chicago Press. (University of Chicago readings in western civilizations, 7.)

Bawden, D. (2001). Information overload. London: South Bank University. (Library and information briefing series, 92.)

Bawden, D., Holtham, C., \& Courtney, N. (1999). Perspectives on information overload. Aslib Proceedings, 51(8), 249-255. doi: 10.1108/EU0000000006984

Butcher, H. (1995). Information overload in management and business. In IEE Colloquium on Information Overload pp.1/1-1/2. London: IEE. doi: 10.1049/ic:19951426

Campbell, D. J. (1988). Task complexity: A review and analysis. The Academy of Management Review, 13(1), 40-52. doi: 10.5465/AMR.1988.4306775

Cooper, G. (1998). Research into cognitive load theory and instructional design at UNSW. Available at: http://webmedia.unmc.edu/leis/birk/CooperCogLoad.pdf 
Corragio, L. (1990). Deleterious effects of intermittent interruptions on the task performance of knowledge workers: A laboratory investigation. (Unpublished doctoral dissertation: University of Arizona.)

Deutsch, K. W. (1961). On social communication and the metropolis. Daedalus, 90(1), 99-110.

Diderot, D. (1755). The definition of an encyclopedia. [Article translated from Diderot's L'Encyclopédie]. In K.M.Baker (Ed.), The Old Regime and the French Revolution (pp.71-88). Chicago: University of Chicago Press, 1987. (University of Chicago readings in western civilizations, 7.)

Dubin, R. (1976). Theory building in applied areas. In M.D.Dunnette (Ed), Handbook of industrial and organizational psychology (pp.17-39). Chicago: Rand McNally College Pub.Co.

Dubin, R. (1978). Theory building. New York: Free Press.

Edmunds, A., \& Morris, A. (2000). The problem of information overload in business organisations: A review of the literature. International Journal of Information Management, 20(1), 17-28. doi: 10.1016/S0268-4012(99)00051-1

Eppler, M., \& Mengis, J. (2004). The concept of information overload: A review of literature from organization science, accounting, marketing, MIS, and related disciplines. The Information Society, 20(5), 325-344. doi:10.1080/01972240490507974

Farhoomand, A. F., \& Drury, D. H. (2002). Managerial information overload. Communications of the ACM, 45(10), 127-131. doi: 10.1145/570907.570909

Feather, J. P. (1998). The information society: A study of continuity and change (2nd ed.). London: Library Association Publishing.

Galbraith, J. (1974). Organization design: An information processing view. Interfaces, 4(3), 28-36. doi:10.2307/25059090

Hall, A., \& Walton, G. (2004). Information overload within the health care system: A literature review. Health Information \& Libraries Journal, 21(2), 102-108. doi:10.1111/j.14711842.2004.00506.x

Herther, N. K. (1998). Push and the politics of the internet. The Electronic Library, 16(2), 109-114. doi: 10.1108/eb045624

Heylighen, F. (2002). Complexity and information overload in society: Why increasing efficiency leads to decreasing control. Available at: http://pcp.vub.ac.be/Papers/PapersFH2.html

Hiltz, S. R., \& Turoff, M. (1985). Structuring computer-mediated communication systems to avoid information overload. Communications of the ACM, 28(7), 680-689.

doi:http://doi.acm.org/10.1145/3894.3895

Holton, E. F., \& Lowe, J. S. (2007). Toward a general research process for using dubin's theory building model. Human Resource Development Review, 6(3), 297. 
Iselin, E. R. (1993). The effects of the information and data properties of financial ratios and statements on managerial decision quality. Journal of Business Finance \& Accounting, 20(2), 249-266. doi:10.1111/j.1468-5957.1993.tb00663.x

Jackson, T. W. (2009). The email optimisation toolkit. London: Ark Group.

Jackson, T. W., \& Lichtenstein, S. (2011). Optimising e-mail communication: The impact of seminarand computer-based training. International Journal of Internet and Enterprise Management, 7(2), 197-216. doi: 10.1504/IJIEM.2011.039915

Jackson, T. W. (2011). Modelling the factors of information overload. Unpublished manuscript.

Jones, Q., Ravid, G., \& Rafaeli, S. (2004). Information overload and the message dynamics of online interaction spaces: A theoretical model and empirical exploration. Information Systems Research, 15(2), 194-210. doi:10.1287/isre.1040.0023

Katzer, J., \& Fletcher, P.T. (1992). The information environment of managers. Annual Review of Information Science and Technology, 27, 227-263.

Keller, K. L., \& Staelin, R. (1987). Effects of quality and quantity of information on decision effectiveness. Journal of Consumer Research, 14(2), 200-213.

Kerr, E. B., \& Hiltz, S. R. (1982). Computer-mediated communication systems: Status and evaluation. Orlando, FL: Academic Press, Inc.

Kirsh, D. (2000). A few thoughts on cognitive overload. Intellectica, 1(30), 19-51.

Klapp, O. E. (1986). Overload and boredom: Essays on the quality of life in the information society. Westport, CT: Greenwood Publishing Group Inc.

Klausegger, C., \& Sinkovics, R. R. (2007). Information overload: A cross-national investigation of influence factors and effects. Marketing Intelligence \& Planning, 25(7), 691-718.

Lynham, S. A. (2000). Theory building in the human resource development profession. Human Resource Development Quarterly, 11(2), 159-178.

Meglio, C., \& Kleiner, B. (1990). Managing information overload. Industrial Management \& Data Systems, 90(1), 23-25. doi: 10.1108/02635579010003405

Meier, R. L. (1963). Communications overload: Proposals from the study of a university library. Administrative Science Quarterly, 7(4), 521-544.

Miller, G. A. (1994). The magical number seven, plus or minus two: Some limits on our capacity for processing information. Psychological Review, 101(2), 343-352. doi: 10.1108/02635579010003405

Miller, J. G. (1960). Information input overload and psychopathology. American Journal of Psychiatry, 116(8), 695-704. doi:10.1176/appi.ajp.116.8.695

Muller, T. E. (1984). Buyer response to variations in product information load. Journal of Applied Psychology, 69(2), 300-306. doi: 10.1037/0021-9010.69.2.300 
Nelson, M. R. (1994). We have the information you want, but getting it will cost you! Held hostage by information overload. Crossroads, 1(1), 11-15. doi: 10.1145/197177.197183

Newell, A., \& Simon, H. A. (1972). Human problem solving. Englewood Cliffs, NJ: Prentice-Hall.

O'Reilly, C. A. (1980). Individuals and information overload in organizations: Is more necessarily better? The Academy of Management Journal, 23(4), 684-696. doi: 10.2307/255556

Owen, R. S. (1992). Clarifying the simple assumption of the information load paradigm. In J.F.Sherry \& B.Sternthal (Eds.), Advances in consumer research, 19, (770-776). Provo, Utah: Association for Consumer Research.

Plumlee, M. A. (2003). The effect of information complexity on analysts' use of that information. The Accounting Review, 78(1), 275-296.

Redman, T. C. (1997). Data quality for the information age. Norwood, MA: Artech House, Inc.

Schick, A. G., Gordon, L. A., \& Haka, S. (1990). Information overload: A temporal approach. Accounting, Organizations and Society, 15(3), 199-220. doi: 10.1016/0361-3682(90)90005-F

Schneider, S. C. (1987). Information overload: Causes and consequences. Human Systems Management, 7(2), 143-153.

Seigler, M. G. (2003). Every two day we create as much information as we did up to 2003. Available at: http://techcrunch.com/2010/08/04/schmidt-data/

Sewall, T. J. (1988). A factor analysis of three learning styles instruments: A test of the Curry model of learning style characteristics. (Doctoral dissertation). University of Wisconsin- Madison.

Shannon, C. E. (1948). A mathematical theory of communication. The Bell Systems Technical Journal, 27, 379-423, 623-656.

Simpson, C. W., \& Prusak, L. (1995). Troubles with information overload: Moving from quantity to quality in information provision. International Journal of Information Management, 15(6), 413425. doi: 10.1016/0268-4012(95)00045-9

Slawson, D. C., Shaughnessy, A. F., \& Bennett, J. H. (1994). Becoming a medical information master: Feeling good about not knowing everything. The Journal of Family Practice, 38(5), 505-513.

Speier, C., Valacich, J. S., \& Vessey, I. (1999). The influence of task interruption on individual decision making: An information overload perspective. Decision Sciences, 30(2), 337-360. doi:10.1111/j.1540-5915.1999.tb01613.x

Stvilia, B., Twidale, M.B., Smith, L.C., \& Gasser, L. (2005). Assessing information quality of a community-based encyclopedia. In F. Naumann, M. Gertz \& S. Mednick (Eds.), Proceedings of the International Conference on Information Quality-ICIQ 2005 (pp. 442-454). Cambridge,MA: MTIQ.

Swain, M. R., \& Haka, S. F. (2000). Effects of information load on capital budgeting decisions. Behavioral Research in Accounting, 12, 171-199. 
Tushman, M. L., \& Nadler, D. A. (1978). Information processing as an integrating concept in organizational design. Academy of Management Review, 3(3), 613-624. doi:

10.5465/AMR.1978.4305791

Wilson, T. D. (2001). Information overload: Implications for healthcare services. Health Informatics Journal, 7(2), 112-117. doi: 10.1177/146045820100700210

Wurman, R. S., Leifer, L., Sume, D., \& Whitehouse, K. (2001). Information anxiety 2. Indianapolis, IND.: Que.

Zull, J. E. (2002). The art of changing the brain: Enriching teaching by exploring the biology of learning. Sterling, VA.: Stylus Pub. 